\title{
9th International Conference on Cryocrystals and Quantum Crystals
}

\author{
Odessa, Ukraine, September 2-8, 2012
}

The 9th International Conference on Cryocrystals and Quantum Crystals (CC 2012) was held in Odessa, Ukraine, September 2-8, 2012. It was organized by Odessa State Academy of Refrigeration in cooperation with B. Verkin Institute for Low Temperature Physics and Engineering, NASU, and Institute of Solid State Physics, RAS. The actual venue of CC-2012 was a spa resort Chabanka, $35 \mathrm{~km}$ east of Odessa downtown, a picturesque secluded recreation center.

The CC 2012 conference heard 19 Invited lectures and 25 orals talks and saw 49 poster presentations. One of the focuses of the conference was the problem of recently discovered high-pressure phases of solid hydrogen. A special ad hoc round table was devoted to this problem. Among other hot topics were solid and superfluid helium (including the problem of supersolid), spectroscopic studies of cryocrystals, and unusual phenomena in the novel carbon materials.

54 participants from 15 countries (Russia, Poland, Kazakhstan, USA, Canada, UK, Germany, Japan, Italy, Spain, China, Finland, France, and Israel) and 36 scientists from Ukraine participated in the conference. Such a considerable number of international participants were largely caused by the specificity of the conference venue, the Odessa city with its spirit of a former porto franco and the good-humored way of life of Odessa inhabitants. Actually, it was for the second time that Odessa hosted a CC conference but the previous one it was way back in the USSR times in 1986.
Odessa city is well-known outside of Ukraine as a unique cultural and scientific center, which has an unusual history and traditions. From the very moment of foundation in the late XVIII century Odessa became an international harbor city; it had broad trade ties in Europe and beyond. The interest to Odessa was promoted by the events that happened in Russia in the early XX century, which were reflected in literature and cinema (especially in the world famous Eisenstein film "Battleship Potemkin"). Several waves of mass emigration from Odessa also helped popularity of Odessa city around the world.

Scientific traditions in Odessa had formed mainly in Novorossiysky University, based at the Richelieu Lyceum, where in due time D. Mendeleev had been lecturing. Such famous physicists as L. Mandelshtam and G. Gamov graduated from Odessa University. Many famous physicists including A. Glauberman, I. Fisher and other worked there. The participants had a chance to get acquainted with Odessa during a day-long excursion to downtown. Luckily, the weather was rather pleasant, warm and sunny, during the whole conference time.

The number of presentation submitted for publication in the conference proceedings turned out to be too numerous to be accommodated within a single journal issue. Therefore, with the agreement of the Editorial Board of Fizika Nizkikh Temperatur, the proceedings will take up the complete May 2013 issue as well as, partly, the next, June issue. The proceedings include 
two short reviews based on the corresponding plenary presentations.

The Organizing Committee of CC-2012 gratefully acknowledge the financial support provided by ICEBLICK Ltd (Odessa, Ukraine) and Institute of Solid State Physics, Russian Academy of Sciences.

The month of this issue marks the 80th birthday of outstanding low-temperature physicist Prof. Vadim G. Manzhelii. He is known not only for his pioneer breakthrough results in the thermodynamics of cryosolids but also as a driving force (together with Prof. Antonina F. Prikhot'ko) that has launched the Cryocrystals (CC) meetings. The first CC meeting was held in March 1997 in Viljandi, Estonia. At first the CC meetings were AllUSSR conferences which later, in the nineties of the last century, became a biannual international issue. The ever accelerating progress in low-temperature physics had inevitably led to appreciable modernizing changes in the scope of the CC Conference, proving its viability. This issue is actually a tribute to the jubilee of Academician Professor Vadim Grigorievich Manzhelii.

Mikhail A. Strzhemechny

Eugene S. Yakub 